Brandstaetter, Thomas, Bamber, David and Weir, David T.H. ORCID: https://orcid.org/0000-0002-67506722 (2016) Wasta: Triadic trust in Jordanian Business. In: Ramady, A., (ed.) The political economy of wasta: use and abuse of social capital networking:. Berlin, Springer, pp. 65-78

Downloaded from: http://ray.yorksj.ac.uk/id/eprint/3912/

The version presented here may differ from the published version or version of record. If you intend to cite from the work you are advised to consult the publisher's version: https://link.springer.com/book/10.1007/978-3-319-22201-1

Research at York St John (RaY) is an institutional repository. It supports the principles of open access by making the research outputs of the University available in digital form. Copyright of the items stored in RaY reside with the authors and/or other copyright owners. Users may access full text items free of charge, and may download a copy for private study or non-commercial research. For further reuse terms, see licence terms governing individual outputs. Institutional Repository Policy Statement

\title{
RaY
}

Research at the University of York St John

For more information please contact RaY at ray@yorksj.ac.uk 
Thomas Brandstaetter, David Bamber and David Weir: (2016e) Wasta: Triadic trust in Jordanian Business: chapter 5 in Mohamed A Ramady: The political economy of wasta: use and abuse of social capital networking: Berlin: Springer 2016

\title{
Chapter 5
}

'Wasta': triadic trust in Jordanian business

\author{
Thomas Brandstaetter, David Bamber and David Weir
}

\section{Introduction : The Hashemite Kingdom of Jordan}

Jordan is part of the Middle East and North Africa (MENA) countries of the Arab world and a special society with a unique history and some distinctive characteristics. Like many of the countries in the region. It is less than a century old, part of the Ottoman Empire until 1918, then under the British Mandate founded as the Hashemite Kingdom of Jordan in 1946, but being effectively created as Transjordan in 1921, and as the Emirate of Transjordan under Emir, later King Abdullah in 1923. The founding narrative of the kingdom emphasizes the role of Abdullah and his grandson: King Hussein, who ruled from 1952 till 1999 as makers of the nation (Wilson, 1981).

The Hashemite dynasty traces its ancestry from the Prophet Mohamed and Hussein's son Abdullah II is the present monarch. Dina, the first wife of King Hussein was born in Cairo and also descended from the Prophet and following her separation from King Hussein went on to marry a high ranking official in the Palestinian Liberation Organization, Muna the second wife and mother of the present King Abdullah was English, Alia, the third was Palestinian, Noor, the fourth an American of Swedish, Syrian and English descent. The monarchy has been rooted in the tribal, Bedouin cultures of the desert, but has also related to the majority which is of Palestinian origin and while King Hussein undertook a salient role as a national and regional leader and emphasized his military credentials he became known as a creative negotiator for regional peace and stability. His Queens were active protagonists for the emancipation of women and for education for all (Layne, 1994). Tribal motifs have become embodied within the discourses of Jordanian nationality and citizenship (Layne, 1989). The Jordanian ruling monarchy has been appropriately described as "resilient" (Anderson, 1991).

This brief review of four royal marriages indicates some of the complexities of Jordanian society, implicated in discourses both of traditional Arab history and of modernization, of stability and change. Thus while the role of women in Jordan has been publicly espoused at the highest level, and higher education for women is an educational objective, still "honour" killing of women who are believed to have dishonoured their family continues to be a feature (Norton, 1993, Nanes, 2003). Likewise although a majority of the population is of Palestinian origin and the country has been the only country in the Arab world to grant citizenship to large numbers of Palestinians and on the geo-political stage publicly supported the PLO, it was King Hussein who openly took arms against the PLO and expelled them from the nation.

The key institution of the Jordanian military showed strong influences from the colonial and mandate period when the Arab Legion under Sir John Glubb, a British soldier became the best military organisation in the Arab world. Other ethnic groups who preserve some elements of distinctive and dual identity include Armenians, Lebanese and part of the Circassian diaspora who left the Caucasus in the Nineteenth Century who constitute around 
$2 \%$ of the population but have been prominent in the army for example (Jaimoukha, 2001). Some of these members of diasporic communities are vocal in their dual loyalties (DerderianAghajanian, 2009). Jordan hosts approximately 200,000 Egyptian workers, and another 80,000 Fillipinos, Srilankans, Indians, Pakistanis, Lebanese, Europeans, and North Americans ("Asiatour, Jordan/People," 2009). More recently the civil society of Jordan has had to cope with the massive influx of refugees from Iraq and Syria (Chatelard, 2003).

The economy of Jordan has never ,unlike other nations for example in the Gulf region, been able to depend on oil and petroleum, though petrodollar remittances have been an important feature (Brynen, 1992). The banking and financial sectors as well as much of the productive private sector industry is dominated by Palestinians, while the tribal interests of the former Transjordanians have been more influential in the public service and government. The realities of national citizenship are influenced by historical discourses so that there is a distinction between two types of citizenship, Jinsiyya, "passport citizenship" implies citizenship with right of abode while Muwatana "democratic citizenship" implies both Jinsiyya plus full access to the civil, political and social benefits of being a citizen (Butenschøn, Davis and Hassassian, 2000)

The complexities of Jordanian organization have been demonstrated by several writers (Rasheed, 2013, Weir, 2000). While the role of women in many Arab countries especially in Saudi Arabia can be characterized as "neo-patriarchal" this is far from an appropriate depiction of organisations in Jordan where there are generally positive attitudes towards the employment of women and to the involvement of husbands in employment decisions, and to a slight preference on the part of managers for women as employees. (Al Kharouf and Weir, 2008). Conversely while Western knowledge and experience are valued in organizational and managerial development, for instance in relation to e-government (El Sheikh, Cullen and Hobbs, 2008) knowledge management it is understood that these techniques need to be calibrated to Jordanian cultural expectations (Sabri, 2005). Without this attention to cultural factors initiatives like TQM have been found to falter (Bani Ismael, 2012).

Jordan is often experienced by visitors and business visitors as a very hospitable society offering business visitors overt invitations to common sociality (Shryock, 2004). In this respect eating together is both a virtual invitation to participate in a ritual that respects the status of a guest at a family table and an expression of expected consociality (Young and Ladki, 1996). Despite decades of overt emphases on "modernizations" of various kinds, it remains clear that Jordanian society is based on familial structures, themselves rooted in actual or virtual membership of extended families, clans or tribes. Homes are important sources of familial and wider identities (Abu Ghazzeh, 1997).

It is expected that members of a family are conscious of their rights and responsibilities to other family members and these obligations are typically extended to those who by invitation or common commitment to business or collective involvements are welcomed by family as their consociates, represented for example by invitations to homes or to dine together (Al Khatib, 2006). This is the origin and legitimation of the discourse of wasta in Jordanian society and the justification of the bonds this created. Another important framing of the wasta connections in Jordanian society is the need to preserve "face" in social and organizational performances (Goffman (1967). Thus as Al Khatib explains invitations to participate in some common activity are often framed in such a way that there is a strong expectation of compliance because to accept an invitation is to honour both parties, while a refusal, explicit or implicit may have the implication of causing offence (Al Khatib, 1994, 1997). 


\section{Historic development of Jordanian institutions}

Although the pre-Islamic Arab-peninsula has seen the emergence of societies based on highly sophisticated and formalized structures of rational organization, particularly in Mesopotamia, and an interaction with other cultures that brought with them systems of bureaucratization and codified law, such as the Roman empire, took place in peripheral areas of Arabia, Arab society before the advent of Islam was pre-modern in its nature. It needs to be emphasised here, that Arab culture at this stage was geographically limited to the areas of the Arab- peninsula and must not be confused with what is known as the Arab world today. The Arabization of areas beyond the Arab heartland, particularly northern Africa and for a limited period the Caliphate of Cordoba in Andalusia, took place centuries after the Islamization of Arabia.

The discussion of the institutional framework of pre-Islamic Arabia is limited to the region of the centre of the Arab-peninsula which is considered the cradle of Arab civilization before its expansion. Before Islam provided a more universal framework for social interaction, the mostly nomadic population relied on a strong tribal structure as bonding social capital that characterized by a high degree of particularism. A state or a codified law was absent and customs and rules could be enforced only through informal institutions. Tribal identity and cohesiveness within the tribe provided islands stability and personal trust in a sea of anarchy. Solidarity within the Arab tribe, vital to the survival of a group in such an environment, was described as "asabiyya" by 14th century sociologist Ibn Khaldun. Strong asabiyya guaranteed the successful organisation of a tribe in such a harsh environment (IbnKhalduon et al., 2005).

The term "tribe" requires a definition at this stage. Tribe or ashira in Arabic is divided in sub- clans called hamula which consist of fahkds and lazam. A hamula is considered the largest politico-administrative unit and an elder serves as a mediator or wasta. "Members of hamulas usually choose their elders on the basis of wisdom, age and generosity." (Al-Rahami, 2008b: 45) The head of an ashira is called a sheikh whose duty it is to secure welfare of the tribe. "It is the sheik's duty to represent his tribe, to act as an arbiter and a judge in litigation, to give consent for marriages and divorces, to protect the feeble, to receive guests and to protect the honour of the tribe." (Al-Rahami, 2008b: 45)

What constitutes a tribe is common ancestry, although it is not necessarily based on actual kinship. Sharing a name and cultivating stories of common roots of stories that bound the collective together like hardship in the desert or a battle against a common enemy provide a narrative that creates a collective feeling which unites several families to an ashira or a tribe. "What makes a person belong to a tribe is not merely successive degrees of genetic relationships- which, after all, every family in the world has - but rather that a person and his/her tribe think the same way; believe in the same principles; assimilate the same values and ethos; act according to the same rules and laws; respect the same hereditary sheikh; live together; defend each other; fight together, and die together." (Ghazi bin Muhammad, 1999:13) Despite the importance of tribal structure in many Arab societies, ambiguities concerning the definition of what makes a tribe exist among experts. While tribal narrative itself emphasises common kinship Ayubi considers tribes rather a mode of social organisation than a group of people actually sharing common ancestry: "Tribalism, however, belongs more closely to the social imaginaire than it does to the facts of genetics." (Ayubi, 1995: 51)

Within the structures of a tribe consensus and consultation were emphasised and participation and communication aimed to prevent marginalization and resulting conflicts. The shura is known as a procedure of decision-making in the tribal society of pre-Islamic 
Arabia. By giving voice to individual members of the tribe, embeddedness and so asabiyya was strengthened, and shura as a check and balance system controlled power of tribal leaders. It is important to emphasise the consultative, participatory and egalitarian aspects of tribal culture. Although tribal leaders or sheikhs were considered authorities, their power was limited. The rule of a sheikh, literally meaning "elder", was not patrimonial but had to be justified (Al- Rahami, 2008b).

\section{Dispute resolution mechanisms}

The physical environment in which Arab tribes were embedded and the mode of production, both made the society particularly prone to intertribal conflict and required the development of strong mechanisms to solve disputes. The dominant mode of production of nomadic and semi-nomadic tribes in Arabia has been pastoralism. Pastoral farming is characterized by three factors that can cause the collapse of entire systems. Both the high mobility of the capital and the low marginal labour-costs that each additional unit of capital is causing, make it very tempting to raid a neighbouring tribe during economic hardship. Whereas in the case of horticultural farming, capital is immobile and an additional unit of capital cannot be utilized unless additional labour can be acquired, the size of a cattle herd can be increased without too much effort.

Apart from integrating additional capital the capital itself is mobile in contrast to capital of a horticultural society, where the harvest can be physically removed but not the capital itself. A third aspect of pastoralism is that it relies on public goods or common pool resources shared by several actors but which require regulated access to prevent unsustainable use. As described in the tragedy of the commons, if scarce and commonly owned resources like water or pasture can be used unrestricted each actor has an incentive to overuse and as a result the resource collapses. (Hardin, 1994)

All these aspects can potentially destabilise a social structure and require mechanisms to regulate social interaction (Eisenstadt, 1992). The social ethos of Arab tribes, emphasising egalitarianism, consultation and participation does not provide a strict hierarchical order or an authority to regulate social life (Ayubi, 1995). As a consequence conflicts had to be solved by an informal system of arbitration and mediation guided by respected but neutral mediators. This system of conflict resolution provided a fundamental pillar that facilitated collective action, created trust and provided bridging social capital in the absence of a codified law. If a dispute got settled through an arbitrator the decisions of the arbitrator were not legally enforceable but depended on the arbitrator's moral authority. The role of arbitrators was not institutionalised and neither did they have to be member of a certain social sphere, what qualified an arbitrator was the reputation and the moral power to enforce arbitration decisions.

Collective responsibility is an essential aspect of tribal justice (Al-Rahami, 2008a, 2008b). If a member of a tribe commits a crime, it is the entire collective that can be held responsible instead of just the individual who actually violates a norm or harms a member of another tribe. According to this tribal ethos, if justice is not been done in the opinion of the tribe of the victim, revenge can be taken. This threat of becoming a victim of revenge sought for the wrongdoings of a member of the same tribe is a normative force that prevents tribal members from deviant behaviour. Particularly in the case of murder, this structure can lead to further bloodshed and violence. This aspect is essential for understanding the requirement for a dispute resolution mechanism that provides solutions which not just punish violation of norms but establish equilibrium between dispute- parties. It is vital that the hurt party agrees with the judgement and that social harmony is re- established between both parties. A solution just based on principles defined ex-ante only paying tribute to a written law but without concern 
for satisfaction of the party which got hurt, seriously threatens social stability under a structure of collective guilt. Mediation and arbitration in the tribal context must not be merely understood as an insufficient mechanism that compensates for the absence of a codified law in premodern times, but rather as a system of institutions that anticipates the social values of the environment out of which it grew. A society based on egalitarianism, consultation, consensus, collectivism and collective responsibility embedded in the economic logic of nomadic pastoralism, requires institutions that emphasise social equilibrium, anticipation and harmony.

Although the institutional environment of pre-Islamic Arabia was marked by the absence of a codified law and a domination of customary tribal norms, in some areas arbitration was a structured process. "Mecca for example, was a flourishing centre of trade that had a rudimentary system of legal administration with public arbitrators appointed that applied some sort of commercial law. In contrast, Medina was an agricultural area with some elementary forms of land tenure which also had a basic justice administration." (Al-Rahami, 2008a:75) Modern Wasta as a multidimensional social phenomenon has grown out of and been shaped by the institutional history of the region.

\section{Wasta and trust}

Wasta as the phenomenon investigated in this book is a complex construct with confusing and partly socially problematic definitions and perceptions. By using the term Wasta, research is almost automatically associated with such undesirable aspects as corruption, cronyism and clientilism. Managers, companies and government officials are eager not to be publicly associated with practices summarised under the vaguely defined term of Wasta. While research on the negative and harmful aspects of Wasta are dominating the academic discourse in this field, the initially unambiguously positive functions in which Wasta is rooted and its effects on modern social organisations is mostly neglected. While Wasta in academic literature as well as in public perception is mostly considered a pre-modern evil and an aspect of Arab culture, even to be ashamed of, the stabilising trust building function it serves, to date has not received the attention by researchers it deserves.

The tradition of Wasta with its many aspects is deeply rooted in the culture and the collective narrative in many countries of the Arab world. This cultural embededdness of Wasta in the region makes it imperative to understand the many facets and the beneficial roles it can fulfil. This research will approach Wasta from an institutional economics perspective and analyse its role in the process of building personal trust in collective action situations in business. Based on interviews conducted in Jordan, it will be outlined how the process of Wasta and the availability of a mediating third party allows trust to emerge in an environment with perceived deficits in formal law enforcement. Besides the normative function of a structural embededness, it will be outlined how this process of trust building is deeply rooted in a cultural narrative and drawing on local traditions. It will be argued that Wasta cannot be judged as a wholesale concept, but contains beneficial dimensions, which need to be considered.

The seminal work of Cunningham and Sarayrah (Cunningham and Sarayrah, 1993) still serves as a cornerstone when defining Wasta. The term Wasta describes a practice of networking and a type of social capital in Arab societies. Wasta in its many dimensions is a cornerstone of social interaction in Jordan and many other Middle Eastern societies. Wasta is derived from the Arab term "yatwassat" which means steering towards the middle.

Traditionally Wasta refers to a process of mediation between two conflicting parties by a third person, called Waseet. Wasta as an idiosyncratic Arab informal institution is traditionally a backbone of social organisation in Arab societies (Cunningham and Sarayrah, 1993; Al- 
Rahami, 2008b; Hutchings and Weir, 2006; Al-Rahami, 2008b).

Wasta is a complex and multidimensional phenomenon with ambiguous ethical connotations. Irrespective of normative aspects Wasta in many forms is an omnipresent phenomenon in modern Jordan and an aspect of daily life of many Jordanians either in interacting with government authorities, in business relations or in cases where disputes need to be settled. "In most interactive events outside the nuclear family Wasta is considered and invoked where possible." (Cunningham and Sarayrah, 1993: 6) Generally Wasta can be understood as intervention on behalf of others or helping others to attain something they could not achieve alone. Be it in the case of dispute resolution or nepotism, Wasta involves one party which is structurally powerful or controls access to resources or both, who intervenes to bring two parties together, either for the benefit for both parties or by abusing asymmetric power to dominate the other party.

\section{Mediation Wasta}

As noted above, Wasta is a complex and multidimensional phenomenon. While historically Wasta was the central mechanism for dispute-solving in pre-Islamic Arab Bedouin societies, the phenomenon associated with the term Wasta has evolved into different practices over time. Cunningham and Sarayrah (1993) distinguished between two types of Wasta and created the terms mediation Wasta and intercessory Wasta. While intercessory Wasta is a type of rent- seeking behaviour, mediation Wasta summarises the traditional functions of mediation and arbitration (Al-Rahami, 2008b).

Mediation Wasta, which has evolved out of Arab traditions, used to be the cornerstone of social organisation in traditional Bedouin cultures of the Arab peninsula. As described by Cunningham and Sarayrah, mediation Wasta is applied to settle disputes in a large number of possible scenarios. A central aspect outlined by them is the importance of mediation Wasta in cases where a dispute has emerged between two members of different tribes. Particularly in situations in which persons have been physically injured or even killed, mediation Wasta is in many cases essential to guarantee social stability and prevent the escalation of the conflict.

A Waseet needs to find a solution which satisfies both parties and avoids the injured party seeking revenge in the future. If Wasta-logic is applied in a dispute in which a member of one family was injured or killed by a member of another family, a notable person is required to chair delegation or a jaha which jointly will aim to find a solution based on mediation (AlRahami, 2008a). Cunningham and Sarayrah mention the legal aspect of this kind of mediation Wasta. In order to prevent the emergence of a long lasting intertribal conflict, government authorities in some cases demand that both parties agree to a mediation Wasta based solution. "If the victim's family refuses the jaha, members of that family may be jailed as a means of coercing them into cooperating and to reduce the likelihood of further bloodshed."

Only after a successful Wasta mediation does a formal trial begin. This procedure mainly applies in cases in which people are killed or injured such as car accidents or homicide. Cunningham and Sarayrah also point out the slightly decreasing significance of such procedures in Jordan. In a case in which a Wasta procedure is required, it is important to find a competent, experienced and generally respected person to act as a Waseet. Traditionally, an elder of a tribe or a shaykh is asked to mediate and use connections as well as charismatic power to solve a conflict. "You reap what you plant" (Cunningham and Sarayrah, 1993: 8), an Arabic saying which summarises the logic of Wasta based arbitration procedures.

The narrative of Wasta mediation emphasises social unity, harmony and reciprocity. 
"Today I or one of my relatives is the victim; tomorrow or a year from now, we may become the defendant. If we do not show forgiveness, mercy, and tolerance to others in their difficult times, we will not be shown tolerance by others when we are in distress." (Cunningham and Sarayrah, 1993: 8) An important aspect of this arbitration function is the perceived honour of serving as a Waseet. Mediating in a conflict is not connected to financial rewards, and even imposes costs on the mediator:

The traditional shaykh leading a delegation of notables did not receive material compensation for his efforts. On the contrary, he might incur expenses by providing a feast honouring a settlement. The mediator's reward from the conflicting parties, their asking God to prolong the mediator's life and to bestow children in abundance, spreading his name and reputation by word of mouth among tribes and encampments (Cunningham and Sarayrah, 1993: 13). As El-Said points out the highest reward a mediator can expect is an enhanced status within the community and looking for material reward is even considered shameful in traditional Wasta (El-Said, 2009).

Besides this almost formal arbitration function of mediation Wasta, it is also used on a more informal level to settle small disputes or disagreements between two parties.

"Furthermore, Wasta may take the form of formal mediation and interference or it could be informal through sponsoring or recommending." (Al-Rahami, 2008a: 202) Wasta must be understood as a traditional backbone of social organisation in Arab societies. With varying degrees of formality Wasta guarantees the enforcement of the property rights of individual or common goods. "On the other hand, people resorted to Wasta as a mechanism to solve local and community disputes, to facilitate the management of common scarce resources..." (ElSaid and Harrigan, 2009: 1328). In case of disagreement Wasta traditionally used to be the central mechanism to resolve an issue. The availability of the mediation function which facilitated the enforcement of agreements protected individuals as well as a collective against opportunism. "One needs Wasta in order not to be cheated in the market place..." (Al-Rahami, 2008a: 201) Mediation Wasta can be understood as a facilitator to enforce agreements and norms formally and informally through the power and intervention of a Waseet.

\section{Intercessory Wasta}

The second dimension of Wasta identified by Cunningham and Sarayrah is a variety of nepotism and cronyism and is mostly considered a harmful practice. Intercessory Wasta is a process in which a broker uses structural power as a gatekeeper to provide access to resources unattainable to the other party. This phenomenon can be found at many levels of Jordanian society. Particularly interaction between individuals and public administration experiences a utilisation of intercessory Wasta. Wasta relations can be used to speed up administrative procedures like issuing a new passport or licence plates for a car, or to get a job to which the applicant would otherwise have no access. Intercessory Wasta is also used to enter university by bypassing formal regulations, or to get access to other government resources (Smith et al., 2012). In all these scenarios one party has either well-established Wasta relations with a gatekeeper or outright bribery is used to gain support by the broker to attain what is desired. Intercessory Wasta is particularly important in the labour market. Considering the difficult economic situation in Jordan, well-paid jobs are scarce and connections to get a job are widely used (Cunningham and Sarayrah, 1993; Hutchings and Weir, 2006; Loewe, 2007). Intercessory Wasta can be understood as a situation in which a broker establishes a connection, for instance between an applicant and an employer, and uses structural power to allow the applicant access to the job. In such a scenario, having "good Wasta" means having connections to an influential person who is willing to provide access to his or her network of personal relations and to act as a patron for the person seeking a favour. In intercessory 
Wasta a middleman is asked to establish a connection, to give testimony on the good reputation of the resource-seeker and aims to convince, for instance an employer, to provide the resource or a job. The complexity of Wasta implies that intercessory Wasta also contains more than one dimension (Cunningham, 1994). The example mentioned above describes one possible scenario of intercessory Wasta. In this case personal connections and networks facilitate access, in other cases the payment of bribes is made for instant services. The two categories differ concerning the social connections that need to be established. In the latter case a service is delivered for a payment, no personal connection is needed in advance nor do remain any social obligations remain open after the deal.

The other category requires building a connection between the resource-seeker and the gatekeeper. Kinship-relations play a significant role in this constellation of favours and social obligations (Loewe, 2007). Considering the complexity of Wasta not every aspect can be discussed as part of this research. "Wasta has many different facets, but mainly describes personal informal networks based on friendship, kin or patron-client relations. Wasta relations, involving reciprocal and co-operative obligations, have expanded to include other significant loyalties such as ethnic or religious groups, political parties or social clubs, as well as friends and acquaintances." (Al- Rahami, 2008a:202)

Figure 1: Dimensions of Wasta

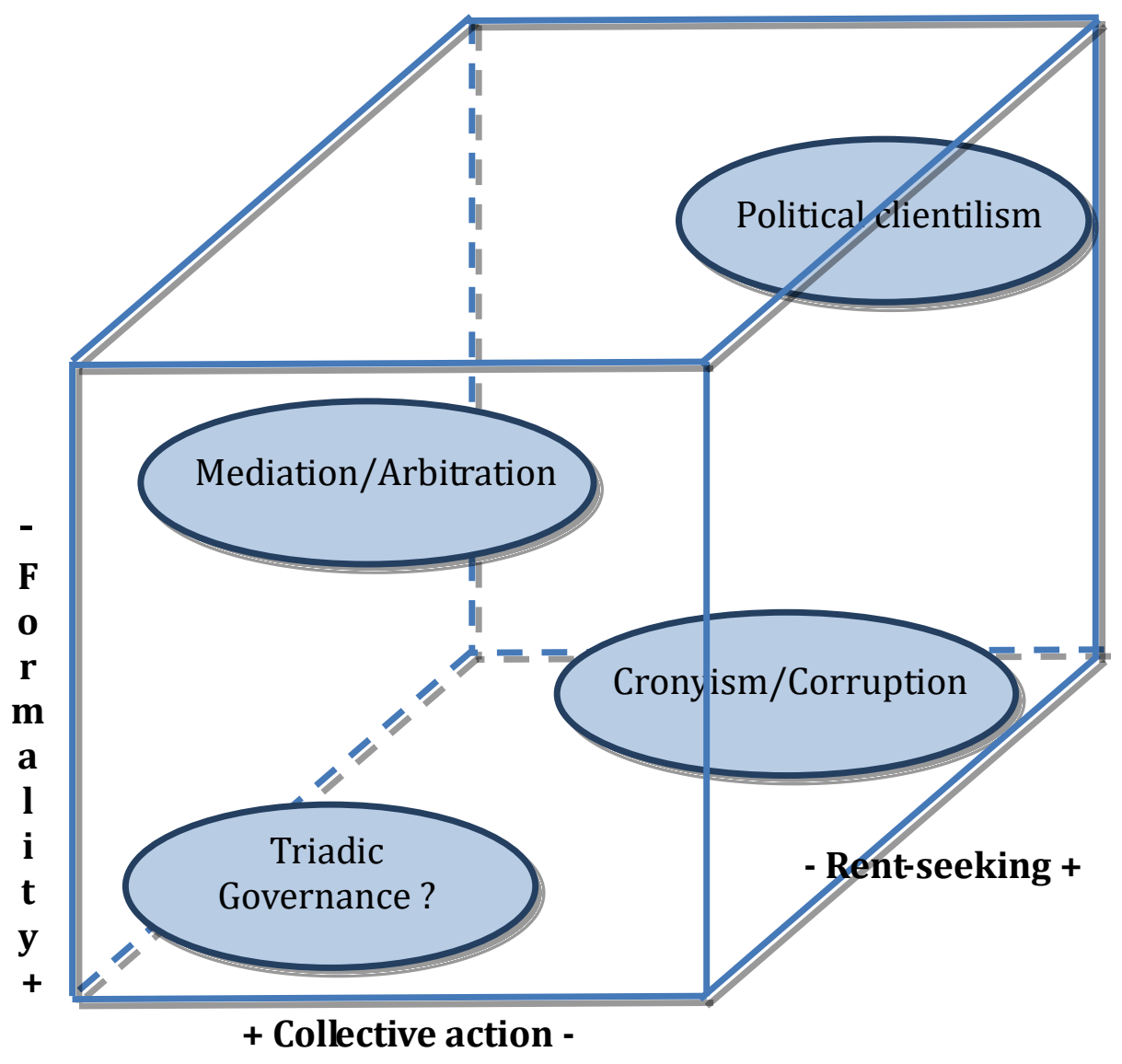

While academic literature deals with intercessory Wasta and with mediation Wasta which is relatively formalised, the informal dimension of mediation Wasta and its trust building function as an economic institution has been mostly neglected by research.

\section{Formality of institutions}


This research aims to contribute to the Wasta discourse by approaching this under researched social phenomenon from an institutional perspective in order to gain a better understanding of the many dimensions and facets it contains. Institutions are the rules, laws, guidelines, traditions and norms that regulate social interaction and vary according to their degree of formality and depend on the cultural setting in which they emerge. Economic institutions vary across societies. Since the type of institutions vary within countries and several societies that are linked by institutions can exist within one country or overlap a country's border, the term society is explicitly chosen at this point instead of referring to the national level. Particularly between societies in which the rule of law is well established and property rights are enforceable and those in which the legal background is less developed, individuals must rely on alternative or what is called self-enforcing means of interaction. The rule of law and third party enforcement are formal institutions in contrast to informal selfenforcing institutions based on personal monitoring (Henisz and Williamson, 1999; De Soto, 2000; Prahalad, 2005; North, 2007). The formality scale illustrated below, summarises the degrees of formality of institutions.

Table 1: Formality scale of institutions

\begin{tabular}{|c|c|c|c|c|}
\hline $\begin{array}{l}\text { Degree of } \\
\text { Formality }\end{array}$ & Institutions & $\begin{array}{c}\text { Hegemonic } \\
\text { Actors }\end{array}$ & $\begin{array}{l}\text { Nature of } \\
\text { Social Ties }\end{array}$ & $\begin{array}{l}\text { Characteristics of } \\
\text { Interaction }\end{array}$ \\
\hline $\begin{array}{l}\text { High:Predomin } \\
\text { antly formal } \\
\text { interactions }\end{array}$ & $\begin{array}{c}\text { Generally } \\
\text { applicable and } \\
\text { legally-binding } \\
\text { laws, } \\
\text { constitutions }\end{array}$ & $\begin{array}{c}\text { State }(+ \\
\text { supranational } \\
\text { actors) }\end{array}$ & $\begin{array}{l}\text { Law and } \\
\text { authority }\end{array}$ & $\begin{array}{c}\text { Written } \\
\text { Communication, legally } \\
\text { binding norms, } \\
\text { rationality, } \\
\text { impersonality, rigidity } \\
\text { of rules, vertical } \\
\text { relations }\end{array}$ \\
\hline $\begin{array}{l}\text { Medium-high: } \\
\text { Mainly formal } \\
\text { interactions }\end{array}$ & $\begin{array}{c}\text { Specific articles } \\
\text { in directives and } \\
\text { contracts }\end{array}$ & $\begin{array}{l}\text { State and } \\
\text { corporate } \\
\text { enterprise }\end{array}$ & $\begin{array}{l}\text { Market and } \\
\text { competition }\end{array}$ & $\begin{array}{c}\text { Mainly written } \\
\text { communication, } \\
\text { codified norms, } \\
\text { impersonality, vertical } \\
\text { relations } \\
\end{array}$ \\
\hline $\begin{array}{l}\text { Medium: Both } \\
\text { formal and } \\
\text { informal } \\
\text { interactions }\end{array}$ & $\begin{array}{c}\text { Modes of } \\
\text { regulation of an } \\
\text { arena }\end{array}$ & $\begin{array}{l}\text { Leaders and } \\
\text { middlemen }\end{array}$ & $\begin{array}{l}\text { Negotiation } \\
\text { and } \\
\text { contestation }\end{array}$ & $\begin{array}{c}\text { Verbal communication, } \\
\text { socially defined } \\
\text { codified norms, } \\
\text { horizontal and vertical } \\
\text { relations }\end{array}$ \\
\hline $\begin{array}{l}\text { Medium-low: } \\
\text { Mainly } \\
\text { informal } \\
\text { interactions }\end{array}$ & $\begin{array}{l}\text { Unexpressed } \\
\text { social norms, } \\
\text { taboos, values, } \\
\text { customs }\end{array}$ & $\begin{array}{l}\text { Community and } \\
\text { peer-groups }\end{array}$ & $\begin{array}{c}\text { Social } \\
\text { control and } \\
\text { identity }\end{array}$ & $\begin{array}{l}\text { Practical knowledge, } \\
\text { verbal communication, } \\
\text { socially defined } \\
\text { codified norms, } \\
\text { horizontals relations } \\
\end{array}$ \\
\hline $\begin{array}{c}\text { Low: } \\
\text { Predominantly } \\
\text { informal } \\
\text { interactions }\end{array}$ & $\begin{array}{c}\text { Personal } \\
\text { agreements }\end{array}$ & Family and friends & $\begin{array}{l}\text { Personal } \\
\text { trust }\end{array}$ & $\begin{array}{l}\text { Practical knowledge, } \\
\text { face to face } \\
\text { communication, } \\
\text { codified norms, } \\
\text { personalised trust, } \\
\text { strong social ties, } \\
\text { intuition }\end{array}$ \\
\hline
\end{tabular}


Considering the historically central role of Wasta as an institution in social coordination, the role of Wasta in building trust in a modern society has to date not been considered by research. An institution which is considered omnipresent and also has a long tradition is likely to be a factor in modern business interaction with its positive and negative aspects. The interviews conducted in Jordan have outlined a perceived deficit of formal institutions and to some extent distrust towards the legal system. Consequently managers and observers interviewed had argued that an informal backup built on personal trust is required in businesses and joint ventures as a protection against opportunism. It has been made very explicit by interviewees that doing business with unfamiliar business partners is not considered an option without a base of trust established prior to any cooperation. This is however not reflecting the effectiveness of the Jordanian legal system, it rather outlines a subjective preference of personal relations as a base of trust over formal ties. The importance of personal trust has emerged as a vital aspect in Jordanian business.

As this research aimed to investigate in Wasta as an indigenous informal institution, the focus has been put on the question how personal trust is created if needed in Jordanian business. Considering the ambiguous connotation of the term Wasta, this term has been avoided in interview questions, giving interviewees the opportunity to describe the trust building process from their perspective. What has emerged from the analysis of interviews is a process of trust building consisting of three main stages.

1. Gathering information about strangers through common third contacts.

2. Approaching unfamiliar business partners through or with references of third parties. (Waseet)

3. Drawing on the normative power of middlepersons or requiring mediation in case of defection. ("Black face" vs. "white face" / Wasata).

A central aspect in all three stages is to varying degrees the function of a middleperson. Either by assisting in gathering information a priori or by activeely supporting the process of introducing two parties, a middleperson has been mentioned consistently during interviews as a cornerstone in this process. Finding a common contact in the network that can provide information about the credibility of persons has emerged to be the first step of trust building by individuals interviewed. The second step of the trust building process also revolves around a third party in between. A reference from a trusted third party supports the credibility of a new potential cooperation partner. Serving as a door opener for an outsider either looking for a business opportunity or a job, is what Cunningham and Sarayrah summarised as intercessory Wasta.

The third stage is providing a normative function for cooperation already set up. A business connection established through a third party is considered protected against opportunistic behaviour due the normative pressure expected from the middleperson as well as the availability of the intermediary as a mediator in case of a dispute. The normative aspect of such a triadic relation consists of two dimensions. One dimension is the loss of reputation suffered by a middleperson in case one business partner to whom a reference has been given abuses trust. In case of defection the middlepersons will lose his or her face or get a "black face". The threat of damaged reputation of a middleperson is expected to prevent giving references for untrustworthy persons.

The second dimension of this normative triad is the expectation that the middleperson 
would intervene and help to settle disputes through mediation. The process described here demonstrates how the categories of intercessory Wasta and mediation Wasta are interrelated. As mentioned by Cunningham and Sarayrah no clear either or exists between these two categories and as described by interviewees, the mediation aspect is considered an assurance for relations established through intercessory Wasta. Although the interrelated nature of both dimensions has been identified and briefly described previously, the role of both Wasta categories as antecedents of personal trust in business relations has so far not been outlined.

The contribution of this research is to reveal that the Wasta procedures are described as the central aspects for trust building in business relations. While intercessory Wasta is considered a harmful or "haram" phenomenon in the discourse, mediation is the beneficial or "halal" aspect of Wasta. The interviews however have revealed that the normative aspects of a relation set up through intercessory Wasta are the primary forces which allow trust to emerge. The importance of this phenomenon for personal trust to emerge needs to be considered in a normative discussion regarding the harms and benefits of Wasta. Besides the probably universal normative forces based on structural embeddedness of a triad and potential intervention of the middleperson, the cultural narrative needs to be emphasised. Interviewees in the business community made explicit references to local and particularly tribal traditions. "It is part of our culture" has been frequently stated during interviews when describing the aspects of mediation and the role middlepersons or Waseets. As described above, mediation has been a pillar of social organisation of Arab societies predating formal institutions in the region.

\section{Conclusion}

The empirical data gathered for this research have revealed a pattern of trust building in Jordanian business. As discussed the Jordanian model of trust building to a large degree rests on the normative power of structural embededdness in triadic relations, the expectation of the Waseet to intervene and the cultural narrative of regional traditions such as mediation, reputation and the threat of the black face. Interviews have clearly emphasised the importance of Wasta as an antecedent of trust in Jordanian business. Although previous publications have dealt with the role of Wasta in Jordan (Cunningham and Sarayrah, 1993; Loewe, 2007) this research provides new insights into the relation between trust and Wasta. The interviews have demonstrated that trust, given it is required, is considered most likely to emerge if a third party or a Waseet establishes a relation and remains available to both parties to intervene or mediate in case of a conflict.

Referring to Cunningham and Sarayah's (1993) concepts of distinction between intercessory Wasta and mediation Wasta, both concepts are intertwined in the process of trust building and cannot be clearly distinguished. Intercession and mediation clearly belong together and the availability of a mediator looms as the shadow of the future already in the process of Intercession allowing trust to emerge. Mediation as a backbone of social organisation in traditional Arab cultures is considered a vital normative function and cannot be distinguished from the intercession process. While Cuningham and Sarayrah have approached Wasta as a phenomenon with potentially beneficial dimension, connotations in the academic discourse are predominantly negative (Schlumberger, 2004; Loewe, 2007).

The stigmatisation of intercessory Wasta as harmful and mediation Wasta as beneficial is not consistent and does not reflect reality of social practice. In a later article Cunningham and Sarayah (1994) revise their initial conceptualisation and consider intercessory Wasta as potentially beneficial if mediation is part of intercession and that there is no clear either/or. Although Cunningham and Sarayah provide a basic approach towards the intertwining 
relation between intercessory and mediation Wasta and the beneficial contribution as a mechanism for social organisation, no clear typology of Wasta and trust is developed.

A vital aspect of the insights gained from this research is the relevance of the phenomenon. This research not only explains the structure of an existing phenomenon but reveals through a grounded theory approach that the described process of trust building is a significant mode of interaction. Since trust building mechanisms based on informal institutions can take many forms the patterns discussed have emerged as the preferred structure of social organisation. It not only describes one of many possible paths but demonstrates the significance of Wasta. No previous research has investigated in antecedents of trust in Jordanian business and revealed Wasta as a core concept in this process:

a) Revealing Wasta as the dominant antecedent of personal trust,

b) Providing a model of Wasta based trust creation and

c) Outlining the relation between mediation Wasta and intercession Wasta in trust building.

The concept of Wasta as a stabilising social force with normative and trust building functions is deeply rooted in institutional traditions of Arab societies. It needs to be understood and its potentially beneficial aspects anticipated. It has far from the purely negative connotations of some critical discourse: it will not disappear any time soon. Wasta in Jordan is a very real and live issue in the analysis of contemporary patterns of activity in business and management. It can be understood as not merely an evidence of long-rooted traditions of native cultural performance but as a response to the challenges of behavioural, cultural and linguistic diversity in a dynamic and evolving society. 